\title{
ANÁLISE ECONÔMICO-COMPARATIVA DE PLANOS DE CULTIVO EM UM SOLO SÓDICO SUBMETIDO A UM MANEJO INTEGRADO DE RECUPERAÇÃO' ${ }^{1}$
}

\author{
Nemézio Moreira de Oliveira Júnior², Raimundo Nonato Távora Costa ${ }^{3}$, \\ Luis Carlos Uchôa Saunders ${ }^{3}$ e José Valdeci Biserra ${ }^{4}$
}

\begin{abstract}
RESUMO
A presente pesquisa foi desenvolvida com o objetivo de se proceder a uma análise econômicocomparativa de três planos de cultivo envolvendo duas safras de curcubitáceas e uma de arroz por ano, em cada plano, em um solo aluvial afetado por sais e submetido a um manejo integrado de recuperação, utilizando-se a renda líquida como parâmetro determinante da melhor alternativa econômica. Três planos de cultivo foram utilizados: 1 . Arroz ( $1^{\circ}$ semestre $)+$ duas safras de melão ( $2^{\underline{o}}$ semestre); 2 . Arroz ( $1^{\circ}$ semestre $)+$ duas safras de melancia ( $2^{\circ}$ semestre); 3 . Arroz ( $1^{\circ}$ semestre) + duas safras de abóbora ( $2^{\underline{ }}$ semestre). A análise dos resultados demonstrou que o primeiro plano,

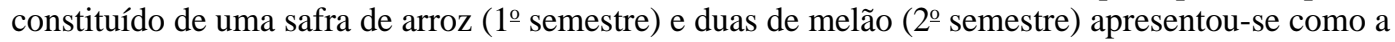
melhor alternativa econômica.
\end{abstract}

Palavras-chave: sodicidade, drenos laterais, análise econômica

\section{COMPARATIVE ECONOMIC ANALYSIS OF CROP PLANS IN A SODIC SOIL UNDER INTEGRATED MANAGEMENT OF RECLAMATION}

\begin{abstract}
The present study was undertaken with the objective to condut a comparative economic analysis of three crop plans involving two harvests of cucurbitaceous and a rice crop in each plan, in an alluvial salt affected soil submitted to integrated management of reclamation, utilising the net returns as a determinant parameter for best alternative. The three crop plans utilized were: 1 . Rice ( $1^{\text {st }}$ Semester) +2 crops of melon musk ( $2^{\text {st }}$ Semester $) ; 2$. Rice ( $1^{\text {st }}$ Semester $)+2$ crops of watermelon ( $2^{\text {st }}$ Semester); 3 . Rice ( $1^{\text {st }}$ Semester $)+2$ crops of Squash $\left(2^{\text {st }}\right.$ Semester $)$. The analysis of results demonstrated that $1^{\text {st }}$ crop plan consisting of one crop of rice ( $1^{\text {st }}$ Semester) and 2 crops of melon musk presented the best economic alternative.
\end{abstract}

Key words: sodicity, lateral drains, economic analysis

\section{INTRODUÇÃO}

A salinização e a sodificação dos solos têm proporcionado, ao longo do tempo, a expansão de áreas com restrições às explorações agrícolas no Nordeste brasileiro. Essas regiões, de solos predominantemente aluviais, caracterizadas por baixos índices pluviométricos e intensa evapotranspiração apresentam baixa eficiência de irrigação, contribuindo para a aceleração do processo de salinização.

\footnotetext{
${ }^{1}$ Parte da dissertação de mestrado apresentada pelo primeiro autor à UFC

2 Mestre em Irrigação e Drenagem, DNOCS, Av. Duque de Caxias 1700, CEP 60035-111, Fortaleza, CE, fone: (085)281-6444, ramal 217

3 Professor Adjunto, Dr; DENA/CCA/UFC, Campus do Pici, Bloco 804, CEP 60455-760, Fortaleza, CE, fone: (085)288-9765.

E-mail: rntcosta@ufc.br.

${ }^{4}$ Professor Titular, aposentado, PhD, CCA/UFC, Fortaleza, CE, fone: (085)244-6498
} 
Na recuperação de solos sódicos, que constituem os de maior grau de degradação, deve-se fazer uso de corretivos que contenham cálcio solúvel, além de práticas mecânicas adequadas.

A deficiência no suprimento de energia elétrica, a escassez de recursos técnicos e financeiros e a qualidade da água de irrigação, dentre outros fatores limitantes, levam o irrigante nordestino a utilizar, em grande escala, a irrigação por superfície, para desenvolver suas atividades olerícolas e frutícolas, especialmente no Vale do Curu, Ceará, onde se desenvolveu a pesquisa.

A recuperação de solos afetados por sais deve seguir uma aplicação criteriosa de tecnologia específica, desenvolvida para as condições peculiares de cada região. Visando propiciar condições favoráveis de umidade, aeração e balanço de sais ao sistema radicular das culturas, faz-se necessária a instalação de um sistema de drenagem subterrânea em áreas irrigadas, o que constitui uma das principais infra-estruturas no processo de dessalinização dos solos, além de prevenir e solucionar os problemas associados à elevação do lençol freático (Soares, 1996).

Costa et al. (1995) realizando análise econômicocomparativa entre espaçamentos de drenos laterais em cultura de milho, concluíram que, para as condições do experimento, o espaçamento de $30 \mathrm{~m}$ entre drenos laterais foi a melhor alternativa econômica, por apresentar maior valor de renda líquida anual.

Com o propósito de se analisar a viabilidade econômica do processo de recuperação de um solo aluvial sódico, procedeu-se a uma análise econômico-comparativa de planos de cultivo, utilizando-se a renda líquida anual como parâmetro determinante da melhor alternativa econômica.

\section{MATERIAL E MÉTODOS}

O estudo foi conduzido na área irrigada DS-2, da Fazenda Experimental Vale do Curu (FEVC) pertencente ao Centro de Ciências Agrárias da Universidade Federal do Ceará, no município de Pentecoste, CE. O solo da área do experimento foi classificado por Coelho (1971) como solo aluvial vértico halomórfico (salino-sódico), horizonte A fraco e textura argilosa. Após sua utilização por sucessivos anos com a cultura do arroz, sob regime de irrigação por inundação, sem um critério de manejo adequado, acentuou-se o processo de degradação do solo na área do experimento, tornando-se um solo sódico.

$\mathrm{Na}$ área do experimento, Costa (1988) realizou práticas de rotação de culturas, adubação verde com feijão de porco, (Canavalia ensiformis, D.C.), aplicação de um melhorador químico (gesso) na dosagem de $17.876 \mathrm{~kg}$ ha $^{-1}$ para reduzir a percentagem de sódio trocável (PST) a 10 até a profundidade de $0,45 \mathrm{~m}$, e tratamentos mecânicos, que se compunham de aração, gradagem e subsolagem, de forma isolada ou em associação. Após a primeira etapa do experimento, a área passou por períodos de cultivo de arroz (Oryza sativa, L.) cultivar IR.8 e pousio, recebendo a incorporação dos restos vegetais na ocasião do preparo do solo.

Realizando um monitoramento do processo de recuperação do solo da área do experimento, Soares (1996) encontrou valores de parâmetros químicos e físico-hídricos, que conferiam melhoria na drenabilidade do seu perfil, através de uma nítida variação no valor da condutividade hidráulica do solo saturado, da ordem de $0,0085 \mathrm{~m} \cdot \mathrm{dia}^{-1}$ para $0,25 \mathrm{~m} \cdot \mathrm{dia}^{-1}$. Na área do experimento, onde se encontra instalado um sistema de drenagem subsuperficial em duplo nível, ou seja, com drenos laterais de alívio localizados em duas profundidades, com base no objetivo da pesquisa, implantou-se o cultivo de melão (Cucumis melo L.) variedade valenciano amarelo, melancia (Citrillus vulgaris), variedade crimson sweet e abóbora (Curcubita maxima) variedade coroa. Cada cultura foi estabelecida no campo em dez linhas de plantio com espaçamento de $1,60 \mathrm{~m} \times 0,80 \mathrm{~m}$, constituindo uma parcela de $2016 \mathrm{~m}^{2}$, individualmente subdividida em seis subparcelas experimentais de dimensões $16 \mathrm{~m}$ x $21 \mathrm{~m}$, conforme mostra a Figura 1. A idéia de se utilizar uma área semelhante àquela controlada na prática por um agricultor, limitou a adoção de um delineamento estatístico, tendo em vista a não disponibilidade de área.

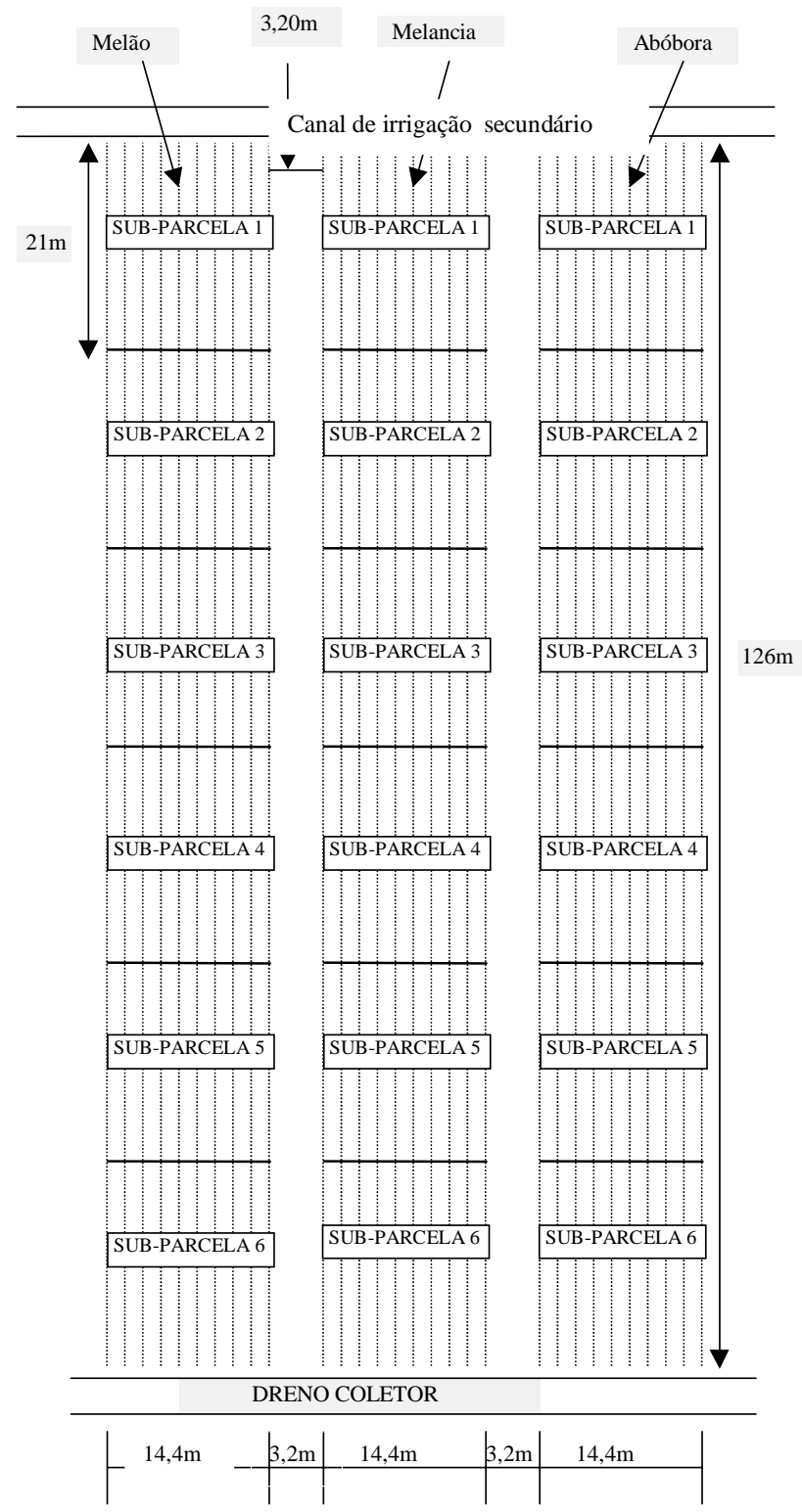

Figura 1. Esquema de campo das parcelas experimentais

A irrigação foi procedida através do sistema de sulcos retos e abertos em declive, constituindo-se na melhor configuração do método de irrigação por superfície para a área do experimento. Visando a um bom desempenho do sistema de irrigação, procedeu-se a uma sistematização (desmontes e/ou aterros) estabelecendo-se um gradiente de declive longitudinal de $0,002 \mathrm{~m} \cdot \mathrm{m}^{-1}$, nivelando-se o terreno na direção transversal. 
A adução de água ao experimento foi realizada de um canal secundário, situado na parte superior da área. Trabalhou-se com uma carga hidráulica de $0,157 \mathrm{~m}$, a qual proporcionava uma vazão de $2 \times 10^{-3} \mathrm{~m}^{3} \cdot \mathrm{s}^{-1}$ em sifões corrugados com diâmetro de $0,05 \mathrm{~m}$ e $2,20 \mathrm{~m}$ de comprimento; as irrigações eram realizadas com base no monitoramento da umidade do solo com o uso de tensiômetros instalados nas profundidades de $0,10 \mathrm{~m}$ e $0,30 \mathrm{~m}$, utilizando-se a equação de Van Genuchten (1980) representativa da retenção de água nas camadas de solo de 0 a 0,20m e de 0,20 a $0,40 \mathrm{~m}$; utilizou-se $-30 \mathrm{kPa}$ como potencial mátrico crítico indicativo, portanto, de quando irrigar, através de monitoramento no tensiômetro a $0,10 \mathrm{~m}$ de profundidade.

A lâmina requerida era aplicada no final do sulco e obtida a partir do respectivo tempo de oportunidade de infiltração após a chegada da frente de avanço, tempo este calculado com base em equação de infiltração obtida através do método de entrada e saída de água no sulco.

O custo da irrigação foi composto pelo custo da tarifa d'água obtida junto ao DNOCS, correspondendo a $\mathrm{R} \$ 11,20 / 1000 \mathrm{~m}^{3}$ (nov, 1996) mais o custo de aplicação, conforme a seguinte equação:

sendo:

$$
\mathrm{CI}=\mathrm{C}_{\mathrm{w}} \cdot \mathrm{W}+\mathrm{C}_{\mathrm{ap}}
$$

CI - custo da irrigação por unidade de área ( $\mathrm{R} \$ / \mathrm{ha})$ $\mathrm{C}_{\mathrm{w}}$ - custo do volume unitário de água aplicado $\left(\mathrm{R} \$ / \mathrm{m}^{3}\right)$

$\mathrm{W}^{\mathrm{W}}$ - volume de água aplicado por unidade de área $\left(\mathrm{m}^{3} / \mathrm{ha}\right)$ $\mathrm{C}_{\mathrm{ap}}$ - custo de aplicação de água por unidade de área ( $\left.\mathrm{R} \$ / \mathrm{ha}\right)$.

Realizou-se uma análise econômico-comparativa de três planos de cultivo, utilizando-se, como indicador para mensurar a eficiência econômica dos planos e, logicamente, identificar o plano mais econômico, a renda líquida anual, definida como:

sendo:

$$
\mathrm{RL}=\mathrm{RB}-\left(\mathrm{A}+\mathrm{COC}+\mathrm{CI}+\mathrm{C}_{\mathrm{md}}\right)
$$

$\mathrm{RL}$ - renda líquida anual do plano de cultivo $(\mathrm{R} \$ / \mathrm{ha})$

$\mathrm{RB}$ - renda bruta anual do plano de cultivo ( $\mathrm{R} \$ / \mathrm{ha})$

COC - custo operacional anual do plano de cultivo ( $\mathrm{R} \$ / \mathrm{ha})$

CI - custo anual da irrigação ( $\$$ \$ha)

$\mathrm{C}_{\mathrm{md}}$ - custo anual de manutenção do sistema de drenagem (R $\left.\$ / \mathrm{ha}\right)$.

Analisaram-se os seguintes planos de cultivo:

1. Arroz $\left(1^{\circ}\right.$ semestre $)+$ duas safras de melão $\left(2^{\circ}\right.$ semestre $)$

2. Arroz $\left(1^{\circ}\right.$ semestre $)+$ duas safras de melancia $\left(2^{\circ}\right.$ semestre $)$

3. Arroz $\left(1^{\circ}\right.$ semestre $)+$ duas safras de abóbora $\left(2^{\circ}\right.$ semestre).

$\mathrm{Na}$ análise, consideraram-se os mesmos níveis de rendimento, preços e custos para a segunda safra de cada uma das curcubitáceas e a condição mais crítica, ou seja, aquela em que os rendimentos das culturas seriam iguais aos obtidos com o antigo sistema de drenagem, enquanto as receitas e os custos para a cultura do arroz referem-se aos obtidos por Costa (1988) dentro do manejo integrado do solo da área do experimento.
Os custos relativos à recuperação do solo, como aquisição e aplicação de gesso, preparo de solo, incorporação de matéria verde, dentre outros, não foram computados na presente pesquisa, tendo em vista a análise econômico-comparativa entre os três planos de cultivo utilizados basear-se em valores relativos da renda líquida anual proporcionado por cada plano; tais custos, porém, comporão necessariamente numa análise de indicadores de rentabilidade da recuperação do solo.

\section{RESULTADOS E DISCUSSÃO}

A Tabela 1 mostra os dados de produtividade das culturas do melão, melancia e abóbora em cada subparcela experimental. Observa-se tendência de queda no rendimento da cultura do melão, a partir da segunda subparcela, a medida em que se distancia do ponto de derivação de água.

Tendo em vista as características do perfil de infiltração de água no solo em irrigação por sulcos abertos, face aos diferentes tempos de oportunidade ao longo da parcela, obtêm-se regiões com lâminas infiltradas que superam a lâmina requerida; por outro lado, a dificuldade de se estabelecer uma função matemática que descreva, com rigor, as características de infiltração do solo, em razão de problemas relativos à variabilidade espacial, permite que, mesmo em se utilizando a estratégia de aplicação da lâmina requerida no final do sulco, ocorram regiões com déficit de umidade acarretando, desta forma, perdas de rendimento acentuadas como as obtidas com a cultura da abóbora. Conforme Scaloppi (1983), devido à variação das características de infiltração com as sucessivas irrigações nos mesmos sulcos ou faixas, recomenda-se determinar os parâmetros da equação de infiltração a cada irrigação. Ademais, aspectos relacionados à variabilidade espacial no teor de sais remanescente, devem ter contribuído, também, na disparidade de rendimento das culturas de melancia e abóbora, ao longo das subparcelas.

Nos estudos conduzidos por Soares (1996) e tendo em vista valores de resistência de entrada da água nos drenos, de acordo com critérios propostos por Dieleman \& Trafford (1976) detectaram-se avarias no desempenho do sistema de drenagem pelo que, no presente estudo, recomendou-se um reinvestimento na instalação de um novo sistema de drenagem subterrânea, composto por drenos laterais assentados a 1,0m de profundidade e espaçados de 20,0m, utilizando-se tubos corrugados flexíveis de PVC e manta de poliéster como envoltório. A profundidade de instalação, embora não seja a ideal para o objetivo proposto, é a que melhor se configura, tendo em vista limitações de cota de saída; já a utilização de referidos materiais de drenagem teve como base estudos desenvolvidos por Costa (1995) no que se refere à homogeneidade, além de menores custos de envelopamento e assentamento dos drenos laterais, se comparados com outros materiais alternativos até então bastante difundidos.

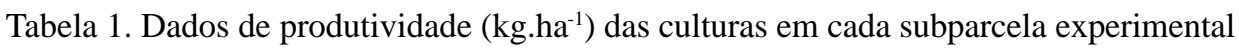

\begin{tabular}{lrrrrrr}
\hline \multicolumn{7}{c}{ S u b p a c e la s } \\
\hline \multicolumn{1}{c}{ Cultura } & \multicolumn{1}{c}{ I } & \multicolumn{1}{c}{ II } & \multicolumn{1}{c}{ III } & IV & \multicolumn{1}{c}{ V } & \multicolumn{1}{c}{ VI } \\
\hline Melão & 8004,40 & 14049,20 & 12834,80 & 9623,00 & 7400,10 & 6621,70 \\
Melancia & 22429,03 & 20963,94 & 22706,99 & 23923,96 & 14881,28 & 10155,22 \\
Abóbora & 18200,51 & 7870,87 & 2672,06 & 896,27 & 996,40 & 1821,61 \\
\hline
\end{tabular}


A Tabela 2 mostra o custo de implantação correspondente ao investimento em 1,0ha de drenagem subterrânea, com drenos instalados a $1,0 \mathrm{~m}$ de profundidade e espaçados de $20,0 \mathrm{~m}$. O custo total de $\mathrm{R} \$ 2.820,00$ corresponde ao valor do investimento inicial necessário para a instalação completa do sistema de drenagem subterrânea, não se considerando possíveis custos iniciais de saneamento e/ou sistematização.

Tabela 2. Custo de implantação de 1,0ha de drenagem subterrânea com drenos instalados a 1,0m de profundidade e espaçados $20 \mathrm{~m}$

\begin{tabular}{lcccc}
\hline Discriminação & & & \multicolumn{2}{c}{$\operatorname{Preço(R\$ )^{*}}$} \\
\cline { 5 - 6 } & Unid. & Quant. & unitário & \multicolumn{1}{c}{ total } \\
\hline Tubos de drenagem & $\mathrm{m}$ & 500,0 & 3,00 & $1.500,00$ \\
Envelope manta poliéster & $\mathrm{m}^{2}$ & 250,0 & 2,00 & 500,00 \\
Escavação manual de valas & $\mathrm{m}^{3}$ & 250,0 & 2,50 & 625,00 \\
Levantamento altimétrico & $\mathrm{d}$ & 2,0 & 30,00 & 60,00 \\
Amarrio manta poliéster & $\mathrm{h} / \mathrm{d}$ & 2,0 & 5,00 & 10,00 \\
Aterro manual de valas & $\mathrm{h} / \mathrm{d}$ & 25,0 & 5,00 & 125,00 \\
\hline TOTAL & & & & $2.820,00$ \\
\hline
\end{tabular}

*Valor real relativo a novembro, 1996

Na avaliação econômica estimou-se a vida útil do sistema de drenagem como igual a 30 anos, de acordo com recomendações da FAO (1986) e, também, captação de recursos financeiros necessários ao investimento, a uma taxa real de juros de $12 \%$ ao ano.

Os custos fixos anuais relativos aos investimentos no sistema de drenagem foram estimados com base no princípio de recuperação do capital, que consiste em determinar o pagamento (amortização) anual necessário para quitar um capital (investimento, empréstimo) em $\mathrm{n}$ anos, com juros compostos sobre o saldo devedor. Utilizando-se um fator de recuperação de capital de 0,1241 obteve-se uma amortização/ano de $\mathrm{R} \$ 349,96$.

No presente trabalho, o valor final ou residual dos investimentos necessários ao sistema de drenagem subterrânea foi considerado igual a zero e os custos variáveis do sistema de drenagem constituíram-se da manutenção anual do coletor, no valor de $\mathrm{R} \$ 100,00$, tendo em vista a operação do sistema ser considerada de custo zero, face o mesmo operar com saída por gravidade e os drenos laterais não terem passado por operação de limpeza.

A Tabela 3 mostra o custo da irrigação por cultura, em 1,0ha. Na composição de referido custo, considerou-se a lâmina média de água aplicada em cada evento de irrigação nas culturas de melão, melancia e abóbora, além da lâmina de irrigação

Tabela 3. Custo da irrigação por cultura em 1,0ha (R\$, nov, 1996)

\begin{tabular}{lcccl}
\hline \multicolumn{5}{c}{ C u l t u r a s } \\
\hline Custos & Melão & Melancia & Abóbora & Arroz \\
\hline $\mathrm{C}_{\mathrm{w}}\left(\mathrm{R} \$ / \mathrm{m}^{3}\right)$ & 0,0112 & 0,0112 & 0,0112 & 0,0112 \\
$\mathrm{~W}\left(\mathrm{~m}^{3} / \mathrm{ha}\right)$ & 5068 & 5068 & 5955 & 12000 \\
$\mathrm{C}_{\mathrm{ap}}(\mathrm{R} \$ / \mathrm{ha})$ & 85,00 & 85,00 & 100,00 & 70,00 \\
$\mathrm{CI}(\mathrm{R} \$ / \mathrm{ha})$ & 141,76 & 141,76 & 166,70 & 204,40 \\
\hline
\end{tabular}

complementar necessária para a cultura do arroz, tendo em vista seu cultivo no período chuvoso; já a Tabela 4 apresenta a renda bruta por safra de cada cultura em 1,0ha e a Tabela 5 comporta os dados econômicos para 1,0ha em cada plano de cultivo, levando-se em conta que o sistema de drenagem deve ser utilizado para produzir duas safras de curcubitáceas e uma de arroz por ano e que os preços se referem a novembro/dezembro de 1996.

Tabela 4. Renda bruta das culturas, por safra, em 1,0ha com drenagem subterrânea

\begin{tabular}{cccc}
\hline Cultura & $\begin{array}{c}\text { Produção física } \\
\text { média }(\mathrm{kg})\end{array}$ & \multicolumn{2}{c}{ Preço(R\$) } \\
\cline { 3 - 4 } & 9755,53 & 0,40 & $3.902,21$ \\
Melão & 19176,73 & 0,19 & $3.643,58$ \\
Melancia & 5409,62 & 0,50 & $2.704,79$ \\
Abóbora & 4710,75 & 0,26 & $1.224,79$ \\
Arroz & & & total \\
\hline
\end{tabular}

Tabela 5. Dados econômicos para 1,0ha em cada plano de cultivo

\begin{tabular}{lrrr}
\hline \multicolumn{1}{c}{ Discriminação } & \multicolumn{3}{c}{ Planos de cultivo } \\
& Plano 1 & Plano 2 & Plano 3 \\
\hline Renda bruta anual(R\$) & $9.029,21$ & $8.511,95$ & $6.634,41$ \\
Custo anual dos investimentos relativos & & & \\
ao sistema de drenagem (R\$/ha) & 349,96 & 349,96 & 349,96 \\
Custo operacional da cultura (R\$ano) & $3.448,50$ & $3.408,50$ & $3.134,50$ \\
Custo anual de irrigação (R\$) & 487,92 & 487,92 & 537,80 \\
Custo anual de manutenção do sistema & & & \\
de drenagem (R\$) & 100,00 & 100,00 & 100,00 \\
Renda líquida anual (R\$) & $4.642,83$ & $4.165,57$ & $2.512,15$ \\
\hline & & &
\end{tabular}

O valor da renda líquida, que constitui o saldo ou resíduo de renda anual que se destina a remunerar a terra e o produtor e a financiar custos não considerados na análise, mostra que, dentro das condições da presente pesquisa, o plano de cultivo constituído de uma safra de arroz $\left(1^{\circ}\right.$ semestre $)$ e duas safras de melão ( $2^{\circ}$ semestre) ou seja, plano 1 , apresentou-se como a melhor alternativa econômica.

Vale salientar que essa conclusão está vinculada às condições estabelecidas pela pesquisa, sendo válida apenas neste contexto. Assim, se outras culturas vierem a ser utilizadas e até outros planos de cultivo investigados, os resultados e, logicamente, as conclusões, poderão ser diferentes, demonstrando a necessidade de pesquisas adicionais futuras que investiguem tais aspectos e até a eficiência de planos de produção alternativos para todos os anos, no horizonte de vida útil dos investimentos no sistema de drenagem, empregando os indicadores econômicos da análise de investimento: relação benefício/custo, valor presente líquido e taxa interna de retorno.

Discutindo a análise de sensibilidade numa avaliação econômica da recuperação de solos salinos no perímetro irrigado de Vaza Barris - Cocorobó, BA, Valdivieso et al.(1988) observaram, no primeiro ano da recuperação, alguns problemas que faziam a área cultivada e a produtividade se tornarem os fatores mais sensíveis da análise. Conforme os autores, tais problemas se constituíam principalmente pelo volume de água fornecido inferior ao requerido e ao deficiente estado de manutenção dos coletores, que limitavam o funcionamento adequado dos drenos subterrâneos. 


\section{CONCLUSÕES}

Nas condições em que a presente pesquisa foi conduzida, a análise e a interpretação dos resultados obtidos permitem evidenciar que:

1. O plano de cultivo constituído de uma safra de arroz $\left(1^{\circ}\right.$ semestre $)$ e duas safras de melão $\left(2^{\circ}\right.$ semestre $)$ apresentou-se como a melhor alternativa econômica, com base no valor da renda líquida anual ( $\mathrm{R} \$ 4.642,83)$.

2. Demonstrou-se a necessidade de pesquisas adicionais futuras que investiguem a eficiência de planos de produção alternativos para todos os anos no horizonte de vida útil dos investimentos no sistema de drenagem, empregando-se os indicadores econômicos da análise de investimento: relação benefício/custo, valor presente líquido e taxa interna de retorno.

\section{REFERÊNCIAS BIBLIOGRÁFICAS}

COELHO, M.A. Características de umidade de alguns solos de aluvião: Normais, sódico e sódico-salino. Rio de Janeiro: UFRJ, 1971. 113p. Dissertação Mestrado.

COSTA, R.N.T. Avaliação de um sistema de drenagem e tratamentos mecânicos na recuperação de um solo sódico no Vale do Curu, CE. Fortaleza: UFC, 1988. 75p. Dissertação Mestrado.
COSTA, R.N.T.; CRUCIANI, D.E.; BISERRA, J.V. Análise econômico-comparativa de espaçamentos de drenos laterais em cultura de milho (Zea mays,L.). Engenharia Rural, Piracicaba, v.6,n.2,p.23-28, Dez.1995.

DIELEMAN, P.J.; TRAFFORD, B.D. Drainage testing. Rome: FAO, 1976. 172p. (FAO: Irrigation and Drainage Paper, 28).

FAO. Drainage design factors; 28 questions and answers. Rome: FAO, 1986. 52p. (FAO: Irrigation and Drainage Paper, 38).

SCALOPPI, E.J. Metodologia para determinação de funções de produção da água. ITEM - Irrigação e tecnologia moderna, Brasília, n.15, p.31-33, 1983.

SOARES, O.H.D. Monitoramento do processo de recuperação de um solo aluvial sódico em condições de drenagem subterrânea. Fortaleza: UFC, 1996. 105p. Dissertação Mestrado.

VALDIVIESO, C.R.; FÉLIX, S.G.; CORDEIRO, G.G. Avaliação econômica da recuperação de solos salinos no perímetro irrigado de Vaza-Barris - Cocorobó, BA. Petrolina: EMBRAPA-CPATSA, 1988. 16p. (EMBRAPACPATSA. Documento, n.48).

VAN GENUCHTEN, M.T.H. A closed-form equation for predicting the hidraulic conductivity of unsatured soils. Soil Sciency Society America Journal, Madison, v.44,p.892-898.1980.

WALKER, W.R.; SKOGERBOE, G.V. Surface irrigation: theory and practice. Englewood Cliffs: Prentice Hall, 1987. 386p. 